\title{
Exploring the Host Parasitism of the Migratory Plant-Parasitic Nematode Ditylenchus destuctor by Expressed Sequence Tags Analysis
}

\author{
Huan Peng ${ }^{1}$, Bing-li Gao ${ }^{2}$, Ling-an Kong ${ }^{1}$, Qing $\mathrm{Yu}^{3}$, Wen-kun Huang ${ }^{1}$, Xu-feng He ${ }^{1}$, Hai-bo Long ${ }^{1,4}$, \\ De-liang Peng ${ }^{1 *}$
}

1 The Key Laboratory for Biology of Insect Pests and Plant Disease, Institute of Plant Protection, Chinese Academy of Agricultural Sciences, Beijing, China, $\mathbf{2}$ Huzhou Modern Agricultural Biotechnology Innovation Center, Shanghai Institutes for Biological Sciences, Chinese Academy of Sciences, Zhejiang, China, $\mathbf{3}$ Eastern Cereal and Oilseed Research Centre, Agriculture and Agri-Food Canada, Ottawa, Ontario, Canada, 4 Key Laboratory of Pests Comprehensive Governance for Tropical Crops, Environment and Plant Protection Institute, Chinese Academy of Tropical Agricultural Science, Danzhou, China

\begin{abstract}
The potato rot nematode, Ditylenchus destructor, is a very destructive nematode pest on many agriculturally important crops worldwide, but the molecular characterization of its parasitism of plant has been limited. The effectors involved in nematode parasitism of plant for several sedentary endo-parasitic nematodes such as Heterodera glycines, Globodera rostochiensis and Meloidogyne incognita have been identified and extensively studied over the past two decades. Ditylenchus destructor, as a migratory plant parasitic nematode, has different feeding behavior, life cycle and host response. Comparing the transcriptome and parasitome among different types of plant-parasitic nematodes is the way to understand more fully the parasitic mechanism of plant nematodes. We undertook the approach of sequencing expressed sequence tags (ESTs) derived from a mixed stage cDNA library of $D$. destructor. This is the first study of $D$. destructor ESTs. A total of 9800 ESTs were grouped into 5008 clusters including 3606 singletons and 1402 multi-member contigs, representing a catalog of $D$. destructor genes. Implementing a bioinformatics' workflow, we found 1391 clusters have no match in the available gene database; 31 clusters only have similarities to genes identified from $D$. africanus, the most closely related species to $D$. destructor; 1991 clusters were annotated using Gene Ontology (GO); 1550 clusters were assigned enzyme commission (EC) numbers; and 1211 clusters were mapped to 181 KEGG biochemical pathways. 22 ESTs had similarities to reported nematode effectors. Interestedly, most of the effectors identified in this study are involved in host cell wall degradation or modification, such as 1,4-beta-glucanse, 1,3-beta-glucanse, pectate lyase, chitinases and expansin, or host defense suppression such as calreticulin, annexin and venom allergen-like protein. This result implies that the migratory plantparasitic nematode $D$. destructor secrets similar effectors to those of sedentary plant nematodes. Finally we further characterized the two $D$. destructor expansin proteins.
\end{abstract}

Citation: Peng H, Gao B-I, Kong L-a, Yu Q, Huang W-k, et al. (2013) Exploring the Host Parasitism of the Migratory Plant-Parasitic Nematode Ditylenchus destuctor by Expressed Sequence Tags Analysis. PLoS ONE 8(7): e69579. doi:10.1371/journal.pone.0069579

Editor: John Parkinson, Hospital for Sick Children, Canada

Received February 9, 2013; Accepted June 10, 2013; Published July 29, 2013

Copyright: (c) 2013 Peng et al. This is an open-access article distributed under the terms of the Creative Commons Attribution License, which permits unrestricted use, distribution, and reproduction in any medium, provided the original author and source are credited.

Funding: This research work were supported by the National Key Basic Research Program of China (973 Program, 2013CB127502), the Special Fund for Agroscientific Research in the Public Interest (number 200903040) and National Natural Science Foundation of China (number 31201493). The funders had no role in study design, data collection and analysis, decision to publish, or preparation of the manuscript.

Competing Interests: The authors have declared that no competing interests exist.

* E-mail: dlpeng@ippcaas.cn

\section{Introduction}

Expressed sequence tags (ESTs) have proven to be one of the most rapid routes to gene discovery of any organism for which a cDNA library is available [1]. In addition, large-scale EST analysis can be used to estimate gene expression levels in specific life stages or tissues and are useful tools for annotation of genome sequences $[1,2]$. EST analysis has been widely applied to study the biology of nematodes. Over 1.5 million ESTs from more than 63 species, including free-living nematodes, animal-parasitic and plant-parasitic species are available in dbEST (GenBank, 1 October 2012). To date, over 125,000 EST sequences from twenty different plantparasitic nematodes are in dbEST. This information is of great significance for studying nematode biology, especially for the identification of effectors.
Plant-parasitic nematode effectors, defined here as proteins secreted by the nematode into the host that manipulate the host to the benefit of the pathogen, are usually expressed in the subventral or dorsal pharyngeal gland cells and then secreted into the host via the stylet [3]. More than 50 effectors have been identified from plant-parasitic nematodes, including effectors that modify cell walls, or manipulate plant cell biology and host defenses [4]. Bioinformatics approaches are widely used for identifying effectors from ESTs. This approach has been used with a wide range of nematode species [5-17]. In the root-knot nematode, Meloidogyne incognita, at least 486 proteins secreted through the stylet have been discovered [18]. Coupled with the increasing availability of plant-parasitic nematode genome sequences [12,19-21] and transcriptome sequences [22-24], it is likely that the complete effector repertoires of plant nematode species will be uncovered in the future. 
Ditylenchus destructor is a migratory plant-parasitic nematode. Overall, some 70 crops and weeds and a similar number of fungal species have been recorded as hosts, of which sweet potato, potato and peanut are the most important. It is a serious pest of potato tubers in Europe and North America, and was also considered as an important international quarantine pest $[25,26]$. In China, $D$. destructor is a major threat to sweet potato production [11,27]. $D$. africanus is another economically important species in the Ditylenchus genus and its partial ESTs had been published [11]. 4847 ESTs from mixed stages of $D$. africanus were clustered into 2596 unigenes, of which $43 \%$ did not show any similarity in to any known genes. 10 putative parasitism genes were identified. $D$. africanus was previously misidentified as $D$. destructor due to their biological and taxonomical similarities [28,29]. However, direct molecular evidences to differentiate the two spacies is lacking.

In this study, we describe the generation and analysis of 9800 ESTs from a $D$. destructor mixed-stage library. Several putative effectors and secreted proteins are identified from this dataset by using bioinformatics approaches. The differences between $D$. destructor and $D$. africanus were also investigated. In addition, two expansin genes present in the dataset were further characterized and their expression profiles were examined by in situ hybridization.

\section{Materials and Methods}

\section{Nematode culture, cDNA library construction and sequencing}

Ditylenchus destructor used in this study was collected in Tongshan city Jiangsu province, China, and was cultured with Fusarium semitectum [30]. Nematodes were collected with sterile distilled water at 3-4 weeks after inoculation. RNA was extracted with TRIzol ${ }^{\circledR}$ Reagent (Invitrogen, Carlsbad, USA), and used to construct the cDNA library with the SMART ${ }^{\mathrm{TM}}$ cDNA Library Construction Kit (Clontech, Mountain View, USA) following the manufacturer's instructions. The resulting fragments were directionally cloned in pDNR-Lib vector. The $D$. destructor mixed stage cDNA library contained over $10^{6}$ primary transformants. Fifty clones were randomly selected and the lengths of their cDNA insert sequences were measured by PCR with M13F and M13R primers (Table 1). 13,237 random colonies were sequenced from the 5' ends using M13 F at the Beijing Genomics Institute (Beijing, China). Sequences were submitted to the EST division of Genbank.

\section{Cleaning and clustering}

The sequences were cleaned using Seqclean (http://www.tigr. org) with a local vector database and default parameter settings, to remove vector, poly (A) and short sequences below 100 nt. EST sequences representing contamination from bacterial, yeast or fungal sources were identified using blast search and removed before further analyses. The dataset was clustered using cluster (http://genome.uiowa.edu/pubsoft/software.html), and assembled sequences were constructed by Phrap (http://www.phrap. org/phredphrapconsed.html) using default settings, generating contigs (clustered ESTs) and singletons (non-clustered ESTs), commonly referred to as "unigenes".

\section{Sequence analysis}

A BLASTX search was performed with all unigenes of $D$. destructor against the NCBI $\mathrm{Nr}$ dataset. BLASTN searches were performed against the NCBI nucleotide database and BLASTP and TBLASTN searches were done against the genomes of $M$. incognita, M. hapla, Bursaphelenchus xylophilus, Globodera pallida and
Heterodera glycines. A TBLASTX search was used against ESTs of 20 species of plant-parasitic nematodes. The BLAST results were classed using a perl script. In addition, $D$. destructor unigenes were used to search against the model species Caenorhabditis elegans (Wormpep v.234) and Brugia malayi. The cut-off for sequence similarity was E-value $<10^{-5}$ for all blast searches.

\section{Translation into putative proteins}

The open reading frames (ORFs) of all identified unigenes were translated by the Genescan prediction and translation programs [31]. Signal peptide prediction was performed with SignalP 4.0 [32] and transmembrane domain prediction was performed by TMHMM (http://www.cbs.dtu.dk/services/TMHMM/).

\section{Functional assignments}

BLAST2GO was used to map and annotate Gene Ontology (GO) terms [33], with default parameters, except for an E-value cut-off of 1e-6, maximum BLAST hits of 30, the conversion of the annotation to GOSlim view, and a node scoring filter in the GO graph of 50 for biological process, 20 for molecular function and 20 for cellular component. The returned results were classed and analyzed using a perl script and WEGO [34]. Further, as an alternative means of assigning function to clusters, clusters were also assigned to metabolic pathway using KOBAS to annotate KEGG [35]; assignments were made by requiring that the highestscoring BLAST matches in SWIR V.21 have an assigned enzyme commission (EG) number.

\section{C.elegans homologues with RNAi phenotype}

To identify cases where $D$. destructor and $C$. elegans share orthologous genes, which have been surveyed in C. elegans for knockout phenotype using RNAi, a local BLASTx search was used against the C. elegans protein database (Wormpep v.234). Results were searched for RNAi phenotype via WormMart section of WormBase (WS220). The sequences of these C. elegans genes with lethal RNAi phenotype were BLASTed against proteins database including plant (rice, maize and Arabidopsis thaliana) and human.

\section{In situ hybridization}

Some candidate effectors were used for in situ hybridization to confirm the expression site as previously described [36,37]. Subsequent linear PCRs were used to synthesize the probes with digoxigenin (DIG)-labelled dNTP (Roche, Mannheim, Germany). The sequences of primers are given in Table 1.

\section{Sequence bioinformatics analysis and phylogenetic tree reconstruction}

The expansin proteins of $D$. destructor and similar sequences were aligned using the ClustalW algorithm in MEGA 5.0 [38]. Phylogenetic analysis of the sequences was performed by the workflow of the Phylogeny.fr platform [39], comprising sequence alignment by the MUSCLE software (v3.7) and removal of ambiguous regions by Gblocks (v0.91b) using the following parameters. The phylogenetic tree was reconstructed from the protein sequences using the maximum likelihood method implemented in the PhyML program (v3.0 aLRT). JTT was used as substitution model with four substitution rate categories; number of invariant sites and gamma distribution parameter were estimated. The gamma shape parameter was estimated directly from the data (gamma $=1.119)$. Reliability of internal branches was assessed using the aLRT test (SH-Like). Graphical representation and edition of the phylogenetic tree were performed with TreeDyn (V198.3) and MEGA 5.0 [38]. 
Table 1. Primers used in this study.

\begin{tabular}{|c|c|c|c|}
\hline Cluster ID & Gene names & primers $\left(5^{\prime}-3^{\prime}\right)$ & Application \\
\hline \multirow[t]{2}{*}{ DDC05000 } & endo-1,4-glucanase & CAGGCTCTGAAATGCTCATGGAA & In situ hybridization \\
\hline & & TGGCAGCGTAGTAGTGCAAAGTG & \\
\hline \multirow[t]{2}{*}{ DDC00149 } & pectate lyase & AAGAAGGTTCCCAAGACCATTAC & In situ hybridization \\
\hline & & TIGCATTAGCCGCTGTAGACAC & \\
\hline \multirow[t]{2}{*}{ DDC04837 } & venom allergen protein & TCAAATTGGCAACCGACCTTTC & In situ hybridization \\
\hline & & AGACCGCTATTCGAGTCACAAG & \\
\hline \multirow[t]{2}{*}{ DDC03578 } & expansin & CATCGAGGCTCAGTTGAATACGC & In situ hybridization \\
\hline & & CCCAGAGGCTCCAGCACAAGAAA & \\
\hline \multirow[t]{2}{*}{ DDC03579 } & expansin & CCTITCTTGTGCTGGAGCCTCTG & In situ hybridization \\
\hline & & GATGGCAATTTGTATTGGTTGGT & \\
\hline \multirow[t]{2}{*}{ DDC03835 } & flp-14 & ПТТСGCCTCACTTТАCCCATCA & In situ hybridization \\
\hline & & GAGTCAGCAGAGCACTACTTTCG & \\
\hline \multirow[t]{2}{*}{ DDC02922 } & annexin & CACCACAGCCAGTGCAGAATC & In situ hybridization \\
\hline & & TGCTCAAGTTGTTGGGACAGA & \\
\hline \multirow[t]{2}{*}{ DDC04384 } & $14-3-3 b$ & GGGCGACTACTACCGCTACTTGG & In situ hybridization \\
\hline & & AGACTGACGCTTAATTGCCTCCA & \\
\hline \multirow[t]{2}{*}{ DDC04927 } & calreticulin & GTTGGGTTGGTTGCCCTGCTC & In situ hybridization \\
\hline & & CATGGACTTTGCGGTTTGATGG & \\
\hline \multirow[t]{2}{*}{ DDC03578 } & expansin-like-1 & GGGCTTGTGGATTGGACATCAG & 3'RACE amplification \\
\hline & & TGTGAATCACGTGGACTTGTCA & \\
\hline \multirow[t]{2}{*}{ DDC03579 } & expansin-like-2 & AGTTGAATAAGCCAGTTCCTGA & 3'RACE amplification \\
\hline & & CGGAGCAACTCTTACATACTTA & \\
\hline \multirow[t]{2}{*}{ DDC03578 } & expansin-like-1 & ССATGTCTAACGCATITATCT & Genomic amplification \\
\hline & & AACGGACTTTATTTCAGTCTACTC & \\
\hline \multirow[t]{4}{*}{ DDC03579 } & expansin-like-2 & GGATGTCTAACGCATITTATCT & Genomic amplification \\
\hline & & САTTCTACAGTCTACTCGGAATT & \\
\hline & M13F & GTAAAACGACGGCCAGTG & sequencing \\
\hline & M13R & GGAAACAGCTATGACCATG & \\
\hline
\end{tabular}

doi:10.1371/journal.pone.0069579.t001

\section{Results and Discussion}

cDNA library construction and EST generation

ESTs were generated from a library constructed from mixed stages of $D$. destructor (Table 2). The cDNA insert lengths ranged in size from about $0.8 \mathrm{~Kb}$ to $3.5 \mathrm{~Kb}$ (not shown). 9800 high quality ESTs were obtained and used for further analysis. The average length of the ESTs was $477 \mathrm{nt}$ and their average GC content was $47.9 \%$. All sequences have been submitted to the dbEST of Genbank under accession numbers (JZ125157-JZ134956).

\section{Cluster analysis and transcript abundance}

The 9800 ESTs were classified into clusters by sequence identity. This analysis yielded 3606 singletons and 1402 contigs. These clusters varied from a single EST (for the 3606 singletons) to 147 ESTs (1 case) (Fig. 1). The top three single clusters account for $3.9 \%$ of the total ESTs, representing 146, 129 and 106 ESTs, respectively. Approximately $85.4 \%$ (1197 out of 1402) contigs were assembled by 2-5 ESTs. The average length of assembled transcript sequences was increased from $449 \mathrm{nt}$ for submitted ESTs alone to $505 \mathrm{nt}$ for the contigs. The longest sequence also increased from 746 tol531 nt. To the first approximation, the project has identified about 5008 clusters with a discovery rate for new genes of $51 \%$ (5008/9800). However, 5008 clusters were likely to be an over estimate of the true gene discovery rate, as one gene could be represented by multiple non-overlapping clusters. A certain degree of 'fragmentation' could be expected in our final

Table 2. CDNA library and ESTs summary of $D$. destructor.

\begin{tabular}{ll}
\hline & \\
\hline Titre of cDNA library (pfu/ml) & $1.4 \times 10^{6}$ \\
cDNA insert size(kb) & $0.8-3.5$ \\
Total cDNA clones picked and sequenced & 13237 \\
Sequences passing quality check & $9800(74 \%)$ \\
Average length of ESTs (nt) & 477 \\
Singletons & 3606 \\
Contigs & 1402 \\
Total number of unigenes & 5007 \\
Average length of unigene (nt) & 507 \\
Number of unigenes with ORF & 4661 \\
Number of unigenes without ORF & 346 \\
\hline doi:10.1371/journal.pone.0069579.t002 &
\end{tabular}




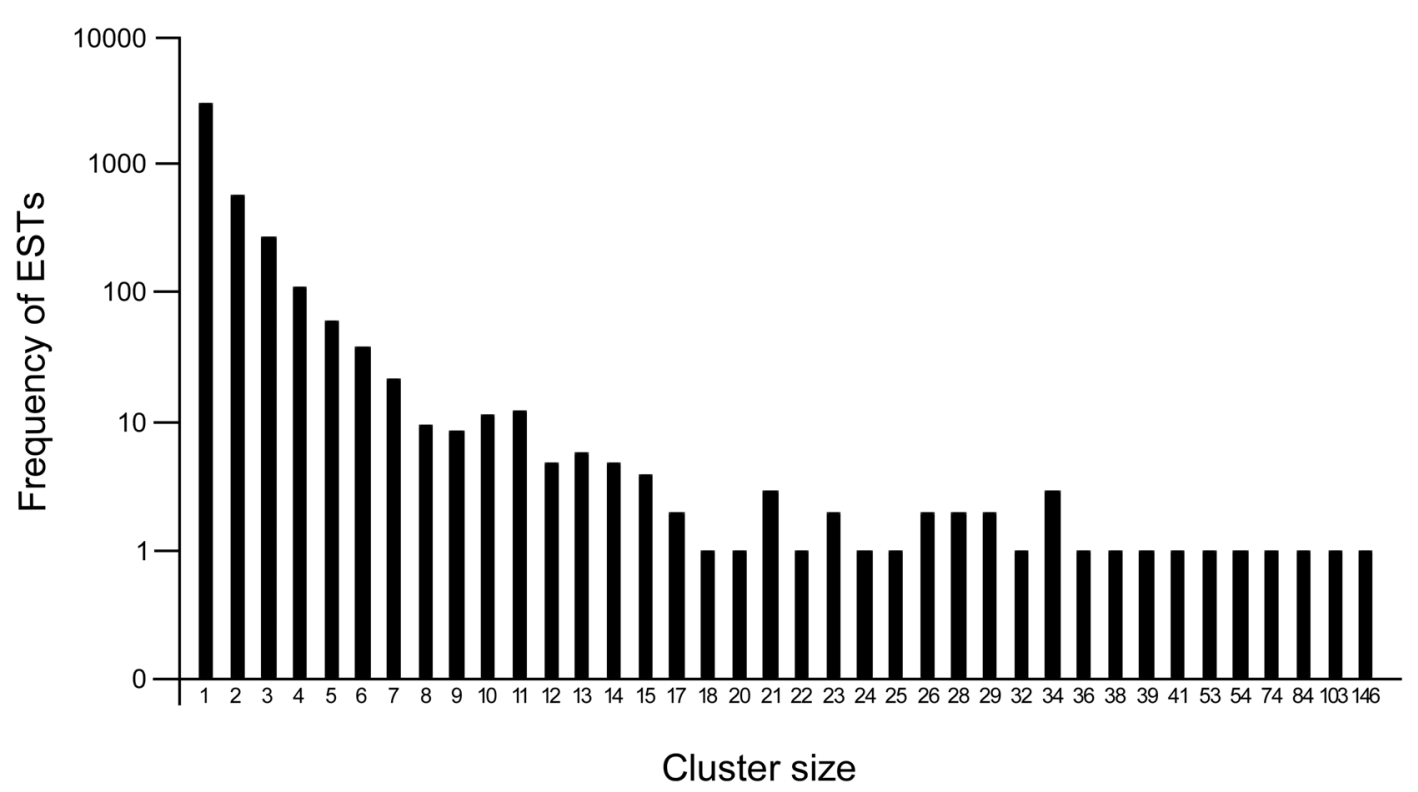

Figure 1. Distribution of clusters by number of assembles ESTs per cluster. $Y$ axis, the number of clusters, $X$ axis cluster size (i.e. the number of ESTs represented by the cluster). doi:10.1371/journal.pone.0069579.g001

dataset and was estimated by EST statistics to be as high as $15.8 \%$ using C. elegans as a reference genome [40]; another method described by Mitreva et al. [41] and resulted in a comparable estimation of $12.9 \%$. After allowing for this fragmentation error $(16 \%)$, we estimated that our dataset represents a minimum of 4206 genes. Assuming between 14,000 and 21,000 total genes, the range encompassed by $M$. incognita [23], B. xylophilus [24], M. hapla [25] and C. elegans (Wormpep v.234), the cluster dataset could represent approximately $20-30 \%$ of $D$. destructor genes.

The top 20 abundantly represented clusters contained $12 \%$ of ESTs (1163 of 9800), and each contained more than 26 ESTs (Table 3). 16 clusters had homologues with non-redundant

Table 3. Top 20 abundant transcripts in the ESTs dataset of $D$. destructor.

\begin{tabular}{|c|c|c|c|c|c|c|}
\hline No. & Cluster ID & ESTs & Top hit species and descriptor & Accession & E-value & \%id \\
\hline 1 & DDC05008 & 146 & No hit (ORF lench282 bp) & 一 & 一 & 一 \\
\hline 2 & DDC05005 & 129 & beta-actin [B. xylophilus] & BAI52958.1 & $1.00 \mathrm{E}-76$ & 62 \\
\hline 3 & DDC05003 & 106 & ASpartyl Protease family member (asp-6) [C. elegans] & NP_505133.1 & $3.00 \mathrm{E}-37$ & 64 \\
\hline 4 & DDC05002 & 86 & beta-actin [B. mucronatus] & BAI52960.1 & $2.00 \mathrm{E}-68$ & 77 \\
\hline 5 & DDC05000 & 79 & GHF5 endoglucanase [A. fragariae] & AFD33558.1 & $2.00 \mathrm{E}-61$ & 55 \\
\hline 6 & DDC04995 & 57 & Hypothetical protein CBG21051 [C.briggsae AF16] & XP_001671832.1 & $3.00 \mathrm{E}-42$ & 48 \\
\hline 7 & DDC04993 & 52 & D-aspartate oxidase $1[$ C. elegans] & NP_504908.1 & $2.00 \mathrm{E}-50$ & 50 \\
\hline 8 & DDC04998 & 51 & Hypothetical protein CBG22199 [C. briggsae AF16] & XP_001667687.1 & $1.00 \mathrm{E}-12$ & 33 \\
\hline 9 & DDC04991 & 50 & No hit (ORF lench 192 bp) & 一 & 一 & 一 \\
\hline 10 & DDC04989 & 43 & tropomyosin fast isoform [Ascaris suum] & ADY44806.1 & $1.00 \mathrm{E}-42$ & 62 \\
\hline 11 & DDC04988 & 42 & UDP-glucuronosyltransferase ugt-48 [Ascaris suum] & ADY44031.1 & $7.00 \mathrm{E}-34$ & 52 \\
\hline 12 & DDC04986 & 41 & No hit (ORF lench279 bp) & 一 & 一 & 一 \\
\hline 13 & DDC04985 & 38 & 4-hydroxyphenylpyruvate dioxygenase [Ascaris suum] & ADY45819.1 & $1.00 \mathrm{E}-54$ & 80 \\
\hline 114 & DDC04984 & 36 & $\begin{array}{l}\text { FAD linked oxidase domain protein [Dyadobacter fermentans DSM } \\
\text { 18053] }\end{array}$ & AYP_003087689.1 & 7E-31 & 42 \\
\hline 15 & DDC04981 & 35 & Hypothetical protein C04F12.8 [C. elegans] & NP_492580.1 & $3.00 \mathrm{E}-56$ & 57 \\
\hline 16 & DDC04975 & 34 & No hit (ORF lench285 bp) & 一 & 一 & 一 \\
\hline 17 & DDC04972 & 31 & heat shock protein HSP70 [Pleurodeles walt] & Q91291.1 & $4.00 \mathrm{E}-88$ & 88 \\
\hline 18 & DDC04997 & 30 & Protein PGHM-1 [C. elegans] & NP_490898.1 & $6.00 \mathrm{E}-17$ & 35 \\
\hline 19 & DDC04960 & 26 & actin-2, partial [Wuchereria bancrofti] & EJW72694.1 & $2.00 \mathrm{E}-33$ & 56 \\
\hline 20 & DDC04968 & 26 & cathepsin B-like proteinase [Diabrotica virgifera virgifera] & XP_001897957.1 & $2.00 \mathrm{E}-16$ & 46 \\
\hline
\end{tabular}

doi:10.1371/journal.pone.0069579.t003 


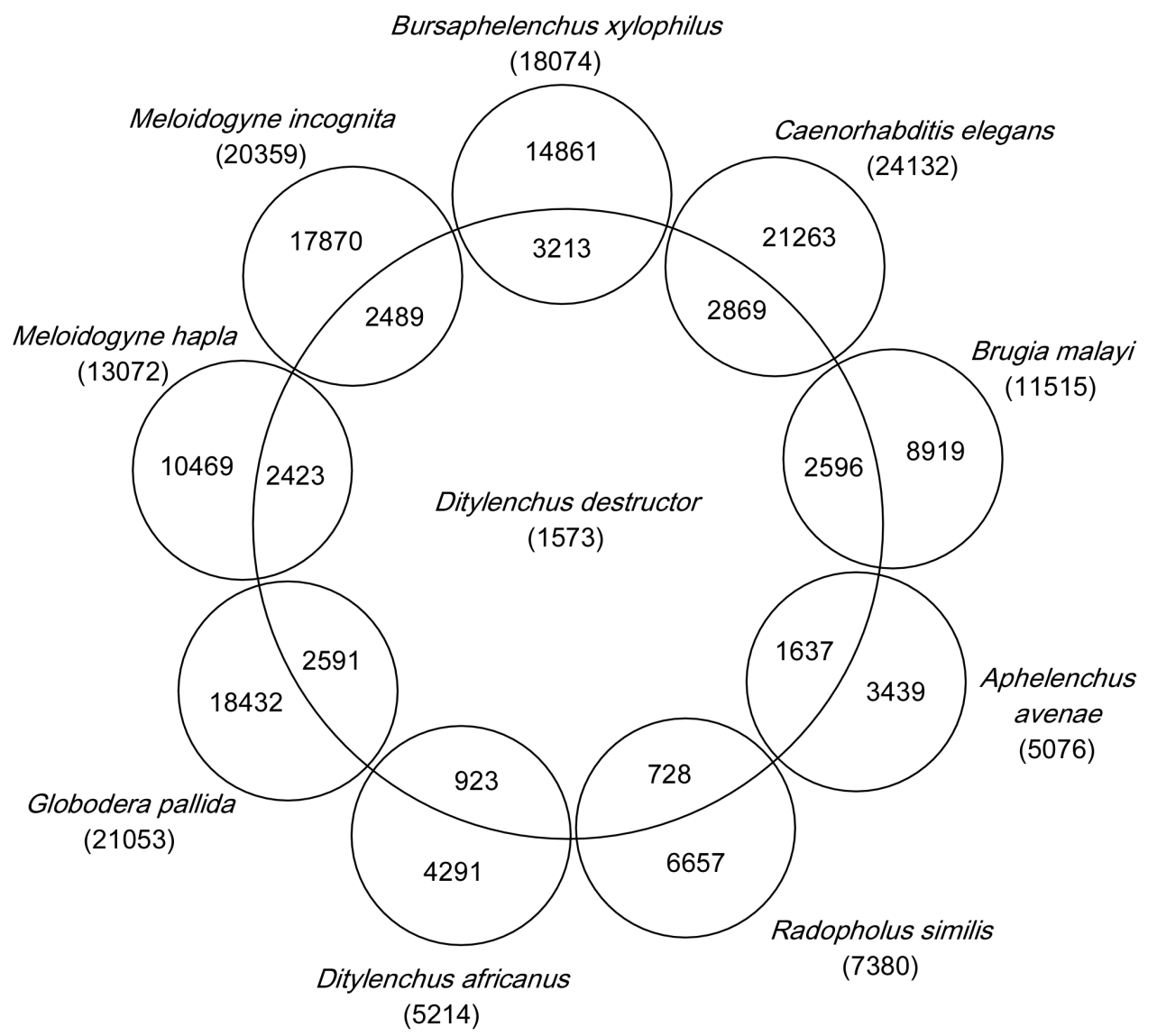

Figure 2. Comparison of $\boldsymbol{D}$. destructor contigs with nematode genomes and ESTs. ESTs including Ditylenchus africanus, Radopholus similis and Aphelenchus avenae, Genomics data including Brugia malayi, Caenorhabditis elegans, Bursaphelenchus xylopilus, Meloidogyne incognita, M. hapla and Globodera pallida. Numbers in parentheses indicate total numbers of contigs. doi:10.1371/journal.pone.0069579.g002

database of NCBI and nematode ESTs. These transcripts primarily represented structural proteins and proteins involved in metabolic processes, such as actin, tropomyosin, aspartyl protease, cathepsin B-like proteinase, D-aspartate oxidase, FAD linked oxidase and UDP-glucuronosyl transferase. Other abundant sequences included three hypothetical proteins, two oxygenases and heat shock proteins. In addition, one of these transcripts represented by 79 ESTs encoded a putative endo-1, 4-gulcanase (ENG), suggesting that the ENG proteins are likely to play important roles in the parasitism and pathogenesis in $D$. destructor, as described for wide arrange of plant-parasitic nematodes [4245]. Among the top 20 most abundant clusters, four clusters of transcripts had no similarity to any sequence in the databases of NCBI and five genomic sequence databases (M. incognita, $M$. hapha, G. pallida, B. xylophilus and H. glycines), suggesting that these genes may have specific functions in the development and parasitism of D. destructor.

\section{Comparative analysis of ESTs}

Approximately $77 \%$ of unigenes of $D$. destructor (3618 of 5008) were similar to other known genes. In the majority of these cases (1244 of 3618), matches were present in all databases searched. Examination of the individual database searches showed that 3245 $D$. destructor sequences were similar to sequences in the NR database, 2869 in C. elegans, 2596 in B. malayi, 2489 in M. incognita, 2423 in M. hapla, 2591 in G. pallida and 3213 in B. xylophilus (Fig. 2). 1297 sequences have homologues in free-living (C. elegans), animal- parasitic (B. malayı) and plant-parasitic (M. incognita, M. hapla, G. pallida and $B$.xylophilus) nematodes, suggesting a role in general nematode development and metabolism. Meanwhile, 413 clusters had good matches exclusively in databases from other plantparasitic nematodes, such as expansin [46], pectate lysases [47], endo-1,4-glucanase etc. The results implied that those genes may play important roles in parasitism and pathogenesis in plantparasitic nematodes.

In addition, we found that 2862 clusters had similarities to the sequences in dbEST derived from other plant-parasitic nematodes, including $18.4 \%$ in D. africanus, $14.5 \%$ in Radophilus similis, $32.7 \%$ in Aphelenchus avenae and $37.2 \%$ in B. xylophilus (Fig. 2). The 15 gene products with the highest level of conservation between $D$. destructor and $D$. africanus are shown in Table 4 . These include gene products involved in metabolism (cathepsin, phosphoenolpyruvate carboxykinase and phosphoribosyltransferase), protein biosynthesis and regulation (HSP90, elongation factor 1A, peroxiredoxin) and cell structure (ubiquitin, myosin and myosin regulatory light chain). In addition, 31 clusters of $D$. destructor were identified with no similarity to known genes except these of $D$. africanus. It is possible that these genes are specific to Ditylenchus spp. D. africanus is closely related to $D$. destructor, but the ESTs matched more homologues in A. avenue $(\mathrm{n}=1638)$ and $B$. xylophilus $(\mathrm{n}=1863)$ than in $D$. africanus $(\mathrm{n}=923)$. We conjectured that the reason may due to the conditions in which the nematodes were cultured. D. destructor, $A$. avenue [12] and B. xylophilus [9] were cultured on fungi, whilst $D$. africanus was cultured on carrot [11]. Therefore, the results may 
Table 4. Top 15 conserved genes between $D$. destructor and $D$. africanus.

\begin{tabular}{|c|c|c|c|c|c|c|}
\hline \multirow{2}{*}{ No. } & \multirow[t]{2}{*}{$\begin{array}{l}\text { D.destructor } \\
\text { clusters }\end{array}$} & \multicolumn{2}{|c|}{ D.africanus ESTs } & \multicolumn{3}{|l|}{ NR database } \\
\hline & & EST No. & E-value & Accession & Top hit species and descriptor & E-value \\
\hline 1 & DDC04778 & DA03582 & $1.00 \mathrm{E}-122$ & АСТ35690.1 & $\begin{array}{l}\text { cathepsin L-like cysteine proteinase } \\
{[D \text {. destructor }]}\end{array}$ & 0.0 \\
\hline 2 & DDC04012 & DA02773 & $1.00 E-120$ & AAL91109.1 & ubiquitin [Onchocerca volvulus] & $2.00 E-134$ \\
\hline 3 & DDC04897 & DA00281 & $1.00 \mathrm{E}-118$ & DAA05871.1 & $\begin{array}{l}\text { eukaryotic translation elongation } \\
\text { factor } 1 \mathrm{~A}[\mathrm{H} \text {. glycines] }\end{array}$ & 3.00E -169 \\
\hline 4 & DDC04016 & DA00057 & 1.00E -115 & ADY43130.1 & $\begin{array}{l}\text { Phosphoenolpyruvate carboxykinase } \\
\text { GTP [Ascaris suum] }\end{array}$ & $6.00 \mathrm{E}-119$ \\
\hline 5 & DDC04283 & DA02680 & $1.00 \mathrm{E}-114$ & ADZ13510.1 & HSP90-1 [D. destructor] & $1.00 \mathrm{E}-126$ \\
\hline 6 & DDC03687 & DA05985 & 1.00E -113 & EGT55546.1 & CBN-EAT-6 protein [C. brenneri] & 0.0 \\
\hline 7 & DDC04006 & DA00450 & $2.00 \mathrm{E}-112$ & XP_001893253.1 & $\begin{array}{l}\text { hypothetical protein Bm1_08910 [B. } \\
\text { malayi] }\end{array}$ & $3.00 \mathrm{E}-26$ \\
\hline 8 & DDC04942 & DA04774 & 1.00E -105 & XP_001892585.1 & $\begin{array}{l}\text { hypothetical protein Bm1_05555 [B. } \\
\text { malayi] }\end{array}$ & $1.00 \mathrm{E}-38$ \\
\hline 9 & DDC03584 & DA00032 & 1.00E -104 & YP_676066.1 & $\begin{array}{l}\text { phosphoribosyltransferase [Chelativorans } \\
\text { sp. BNC1] }\end{array}$ & s 3.00E -61 \\
\hline 10 & DDC00816 & DA02886 & $2.00 \mathrm{E}-98$ & EJW77548.1 & $\begin{array}{l}\text { serine/threonine protein phosphatase } \\
2 \mathrm{~A} \text {,partial [Wuchereria bancrofti] }\end{array}$ & $1.00 \mathrm{E}-93$ \\
\hline 11 & DDC03033 & DA00221 & $2.00 \mathrm{E}-96$ & GAA55031.1 & ubiquitin C [Clonorchis sinensis] & 5.00E -104 \\
\hline 12 & DDC02696 & DA01325 & $1.00 \mathrm{E}-94$ & ADY46489.1 & $\begin{array}{l}\text { SWI/SNF-related matrix-associated } \\
\text { actin-dependent regulator of chromatin } \\
\text { subfamily B member } 1 \text { [Ascaris suum] }\end{array}$ & $1.00 \mathrm{E}-71$ \\
\hline 13 & DDC04656 & DA04271 & $3.00 E-93$ & ADY47037.1 & $\begin{array}{l}\text { Phosphate carrier protein, partial } \\
\text { [Ascaris suum] }\end{array}$ & $9.00 \mathrm{E}-77$ \\
\hline 14 & DDC02743 & DA00825 & $7.00 \mathrm{E}-93$ & ADM35958.1 & $\begin{array}{l}\text { peroxiredoxin } 1 \text { precursor } \\
\text { [Haemonchus contortus] }\end{array}$ & $2.00 \mathrm{E}-67$ \\
\hline 15 & DDC04847 & DA04271 & 3.00E -91 & AAL40718.1 & $\begin{array}{l}\text { myosin regulatory light chain } \\
{[M \text {. javanica] }}\end{array}$ & $8.00 \mathrm{E}-46$ \\
\hline
\end{tabular}

not fully represent the phylogenetic relationship and the genome differences between the two nematodes. However, the results at least reflected the differences of gene expression between different culture methods.

1391 clusters $(27.8 \%)$ had no similarity to any sequences in the databases tested. These clusters had a shorter average sequence length $(423 \mathrm{bp})$ than the unigenes that produced matches in the databases (536 bp). The sequences with unknown origin could correspond either to non-coding sequences (392 clusters without ORF), regulatory and structural RNA or to novel protein coding genes. Alternatively, they may be derived from $3^{\prime}$ untranslated regions and thus did not produce matches during similarity searches.

\section{Functional classification of ESTs}

After mapping a total of 6561 gene ontology $(\mathrm{GO})$ terms to the unigenes, 1991 clusters (39.8\%) were annotated (Fig. 3). 1841 clusters generated matches in the Molecular Function class and retrieved 3768 GO terms, 1381 in the Biological Process with 1942 GO terms and 734 in the Cellular Component class with 851 GO terms. The highest GO term in the Molecular Function class was binding (GO: 0005488), including nucleotide binding (GO: 0000166) (20.2\%), nucleic acid binding (GO: 0003676) (12.1\%)), catalytic activity (GO: 003824) with hydrolase activity (GO: 0016787) (19.4\%) and transferase activity (GO: 0016740) (12\%). Within the Biological Process class, the cellular process (GO: 0009983) (29.9\%), cellular metabolic process (GO: 0008152)
$(23.5 \%)$ categories were the most represented followed by biosynthetic process (GO: 0009058) (9.6\%). For the Cellular Component class, the intracellular (GO: 0044424) (31.6\%) and membrane (GO: 0016020) (20.9\%) are the most highly represented (Table S1).

As an alternative method of categorizing cluster sequences by biochemical function, sequences were assigned to biological pathways using the Kyoto Encyclopedia of Genes and Genomes (KEGG) database (http://www.genome.ad.jp/kegg). 1550 clusters $(31 \%)$ were assigned to enzyme commission (EG) numbers and 1211 clusters mapped to 181 KEGG biochemical pathways (Table 5). The KEGG pathways relating to metabolism were well represented by $D$. destructor sequences, including amino acid metabolism $(n=175)$, carbohydrate metabolism $(n=156)$, xenobiotics bio-degradation metabolism (88 enzymes), lipid metabolism $(\mathrm{n}=86)$, energy metabolism $(\mathrm{n}=76)$ and six other metabolism pathways $(\mathrm{n}=207)$. About $13.7 \%$ of the unique sequences belonged to the genetic information processing (GIP) category. The KEGG pathways strongly represented in GIP are folding, sorting and degradation $(n=51)$, transcription $(n=37)$, translation $(n=30)$ and replication and repair $(n=44)$. Of these, $8 \%$ of the unique sequences belonged to the environmental information processing (EIP) category, indicating higher activities of stress and chaperone related genes during unfavorable conditions. The KEGG pathways strongly represented in EIP include signal transduction (100 enzymes), membrane transport (5 enzymes), and signaling molecules and interaction (4 enzymes). In addition 
a

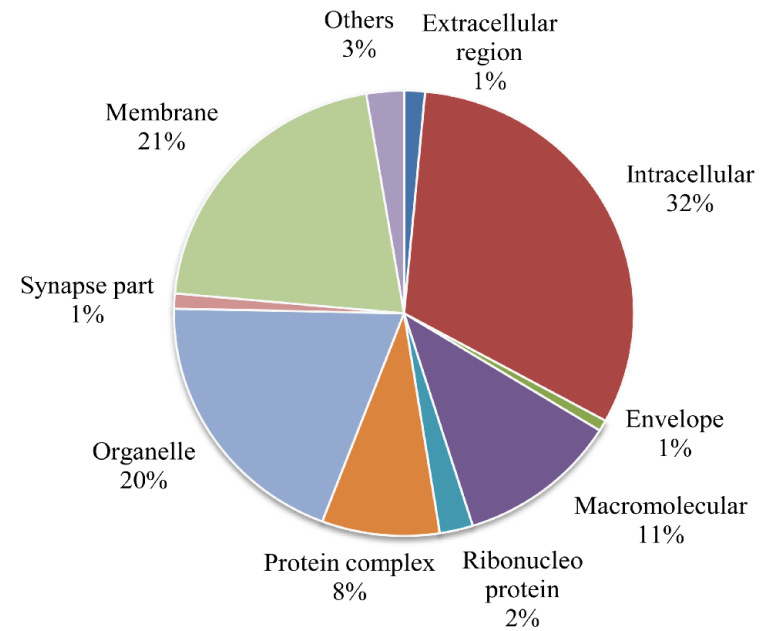

b

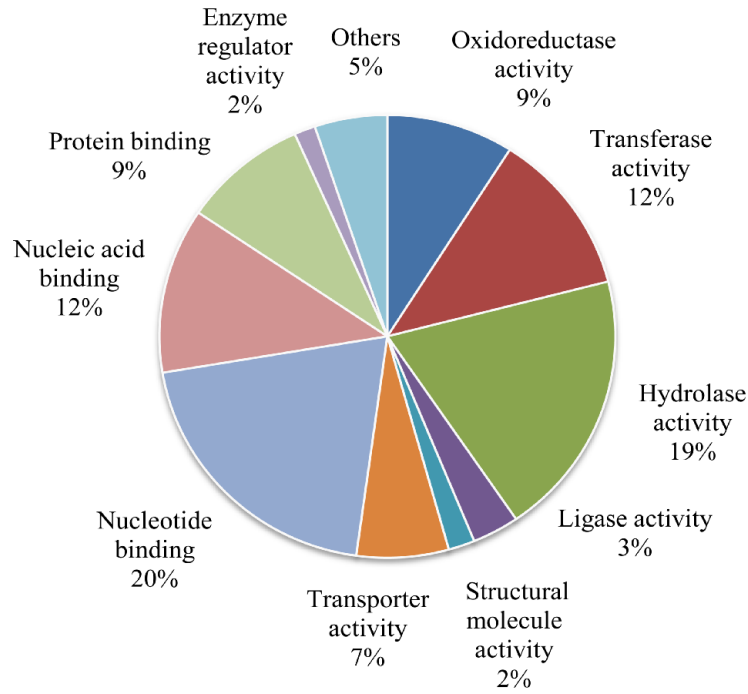

C

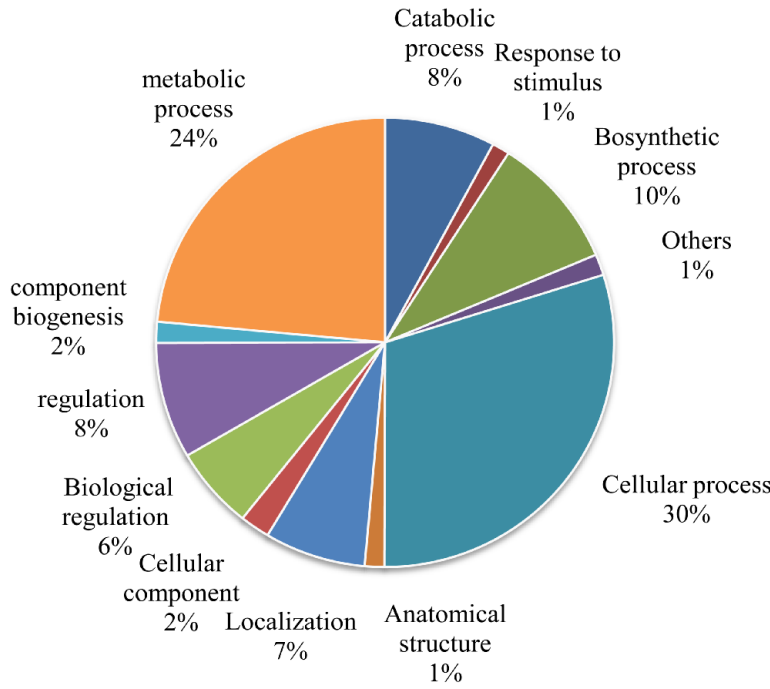

Figure 3. Assignment of Gene Ontology (GO) terms for clusters. Components including Cellular Component (A), Molecular Function (B) and Biological Process (C), are indicated. Individual GO categories have multiple mapping. Percentage reflects the total categories annotated but not the total sequences annotated under each component. doi:10.1371/journal.pone.0069579.g003
$22.5 \%$ of sequences mapped to the cellular processes category. The immune system $(n=56)$, endocrine system $(n=49)$, cell growth and death $(n=49)$, transport and catabolism $(n=43)$, cell communication $(n=37)$ and other pathways $(n=66)$ were also the well represented categories in cellular processes (Table 4).

\section{RNAi phenotypes}

In planta RNAi is one of the proposed strategies to control plantparasitic nematodes $[48,49]$. RNAi phenotypes were assigned to the unigenes on the basis of similarity with C. elegans proteins. 2869 unigenes from $D$. destuctor were similar to those of $C$. elegans. 2137 different C. elegans proteins were retained by removing redundant protein hits. With the 1442 unigenes $(50.3 \%)$ having a C. elegans homologue, an RNAi phenotype was retrieved from Wormmart database. $71.8 \%$ the RNAi phenotypes $(n=1036)$ report a lethal effect. These sequences were compared with the proteins of plants (rice, maize and Arabidopsis thatiana) and human, resulting in 63 genes without similarity. While disruption of gene expression of these genes is expected to have a less profound influence on nematode survival, the strongest effects on nematode survival are expected when targeting genes involved in developmental processes. Therefore, these nematode-specific genes are potential candidates for parasitic control.

\section{Identification of candidate effectors}

22 sequences with similarities to effectors from other plantparasitic nematodes were identified within the ESTs, including a series of plant and fungi cell wall degrading enzymes (Table 6). Four ENG genes were represented in four different clusters. Three of them show greatest similarity to $A$. fragariae cellulase gene, while one has a higher similar to $D$. africanus cellulase gene. Two expansin-like proteins were identified with the best match to the expansin-like genes from $D$. africanus. One cluster has a high similarity with the pectate lyase gene of $A$. avenae, and was confirmed to be specifically expressed in the subventral pharyngeal gland cells of $D$. destructor by In situ hybridization (Fig. 4 a-d).

In the $D$. destructor ESTs, we found two clusters have significant similarity to 1, 3(4)-beta-glucanase protein of the GHF16 family. 1,3(4)-beta-glucanase genes had been also identified in the fungieating plant-parasitic nematodes Bursaphelenchus spp.[50], A. avenae [12] and $P$. coffeae [23]. There are two ESTs similar to the chitinase genes of fungi and Ascaris suum, but they do not match to the reported chitinase gene of plant-parasitic nematodes. Chitinases cleave the 1, 4-glycosidic bonds of chitin and have been found in a wide range of nematodes $[9,12,51]$. Since the chitin and glucan the major structural polysaccharides of the fungal cell wall, chitinases and beta-1, 3-glucanase are important in the breakdown of fungal cell walls and may facilitate feeding on fungi for nematodes like $D$. destructor, Bursaphelenchus spp. and $A$. avenae. However, both of the genes have not been found in another fungal feeding plantparasitic nematode, D. africanus [11]. One possible reason is that D. africanus was cultured on plants, and the expressions of genes relative to fungal substrates were not induced.

Several D. destructor ESTs are the homologues of other reported effectors. Included are venom allergen antigen-like protein, calreticulin, annexin, 14-3-3b, pharyngeal gland cell secretory protein and Sec-2. By in situ hybridization, the expressing patterns of venom allergen antigen-like protein was restricted to the subventral gland cells of $D$. destructor (Fig. 4 e) and calreticulin, annexin and 14-3-3b were expressed in the dorsal gland cell (Fig. 4 $\mathrm{f}-\mathrm{h})$. Venom allergen antigen-like protein, calreticulin and annexin have been reported as the key effectors in plant defense suppression and play an important role in nematode infection 
Table 5. KEGG biochemical mapping for D. destructor clusters.

\begin{tabular}{|c|c|c|c|}
\hline KEGG pathway & clusters & Enzymes & Percentage (\%) \\
\hline 01100 Metabolism & 862 & 641 & 55.1 \\
\hline 01101 Carbohydrate Metabolism & 224 & 156 & 14.3 \\
\hline 01102 Energy Metabolism & 76 & 60 & 4.9 \\
\hline 01103 Lipid Metabolism & 92 & 70 & 5.9 \\
\hline 01104 Nucleotide Metabolism & 46 & 41 & 2.9 \\
\hline 01105 Amino Acid Metabolism & 175 & 134 & 11.2 \\
\hline 01106 Metabolism of Other Amino Acids & 46 & 38 & 2.9 \\
\hline 01107 Glycan Biosynthesis and Metabolism & 23 & 20 & 1.5 \\
\hline 01108 Biosynthesis of Polyketides and Nonribosomal Peptides & 2 & 1 & $<1$ \\
\hline 01109 Metabolism of Cofactors and Vitamins & 45 & 33 & 2.9 \\
\hline 01110 Biosynthesis of Secondary Metabolites & 45 & 31 & 2.9 \\
\hline 01111 Xenobiotics Biodegradation and Metabolism & 88 & 57 & 5.6 \\
\hline 01120 Genetic Information Processing & 214 & 162 & 13.7 \\
\hline 01121 Transcription & 43 & 37 & 2.7 \\
\hline 01122 Translation & 53 & 30 & 3.4 \\
\hline 01123 Folding, Sorting and Degradation & 62 & 51 & 4.0 \\
\hline 01124 Replication and Repair & 56 & 44 & 3.6 \\
\hline 01130 Environmental Information Processing & 137 & 109 & 8.8 \\
\hline 01131 Membrane Transport & 22 & 5 & 1.4 \\
\hline 01132 Signal Transduction & 111 & 100 & 7.1 \\
\hline 01133 Signaling Molecules and Interaction & 4 & 4 & $<1$ \\
\hline 01140 Cellular Processes & 351 & 300 & 22.4 \\
\hline 01151 Transport and Catabolism & 48 & 43 & 3.1 \\
\hline 01141 Cell Motility & 15 & 14 & $<1$ \\
\hline 01142 Cell Growth and Death & 59 & 49 & 3.8 \\
\hline 01143 Cell Communication & 46 & 37 & 3.0 \\
\hline 01150 Circulatory System & 15 & 14 & $<1$ \\
\hline 01144 Endocrine System & 63 & 49 & 4.0 \\
\hline 01145 Immune System & 62 & 56 & 4.0 \\
\hline 01146 Nervous System & 28 & 24 & 1.8 \\
\hline 01147 Sensory System & 4 & 3 & $<1$ \\
\hline 01148 Development & 7 & 7 & $<1$ \\
\hline 01149 Behavior & 4 & 4 & $<1$ \\
\hline
\end{tabular}

success [52-54]. 14-3-3b protein expressed in the dorsal gland of infective second-stage juveniles (J2) has been identified as being present in the secretome of $M$. Incognita. This gene may involve in guide protein-protein interactions and has essential roles in hormonal signal transduction processes in plants [55].

The full EST dataset was analyzed for putative secreted proteins with signal peptides but without a transmembrane domains [56]. The results showed that 634 clusters had signal peptides and 391 of these had no transmembrane domain. 191 of these proteins $(47 \%)$ were found to have significant similarity to known sequences at NR database. Most of candidate effectors of $D$. destructor were present in this list except 14-3-3b, and over 50 clusters were termed as hypothetical proteins. 200 proteins have no significant similarity with known proteins; these may include novel effectors and their functions needs to be confirmed in the future (Table S2). We also found the transcript of a putative secreted protein that encodes a putative FMRFamide-like peptides
(DDC00459) that is enriched in the circumpharyngeal nerve ring of $D$. destructor (Fig. 4 i).

\section{Characterization of two expansin genes}

Expansin proteins secreted by plant-parasitic nematodes loosen plant cell wall components, and have been functionally characterized in several plant-parasitic nematodes [57-60]. In D. destructor

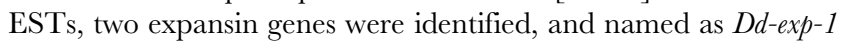
and $D d-\exp -2 . D d-\exp -1$ has highest similarity to the expansin gene of $D$. africanus, while $D d-\exp -2$ has highest similarity to the expansin gene of B. xylophilus. The full length cDNAs of $D d-\exp -1$ and $D d-\exp -$ 2 were obtained by rapid-amplification of cDNA ends (RACE).

The full length cDNA of Dd-exp-1 (Genbank accession No. GU373911) is 1,207 base pair (bp) with a 930 bp open reading frame (ORF). The ORF encodes 309 amino acids with a putative ATG start codon at position 166 and TAG termination codon at position 1,096. The full length cDNA of Dd-exp-2 

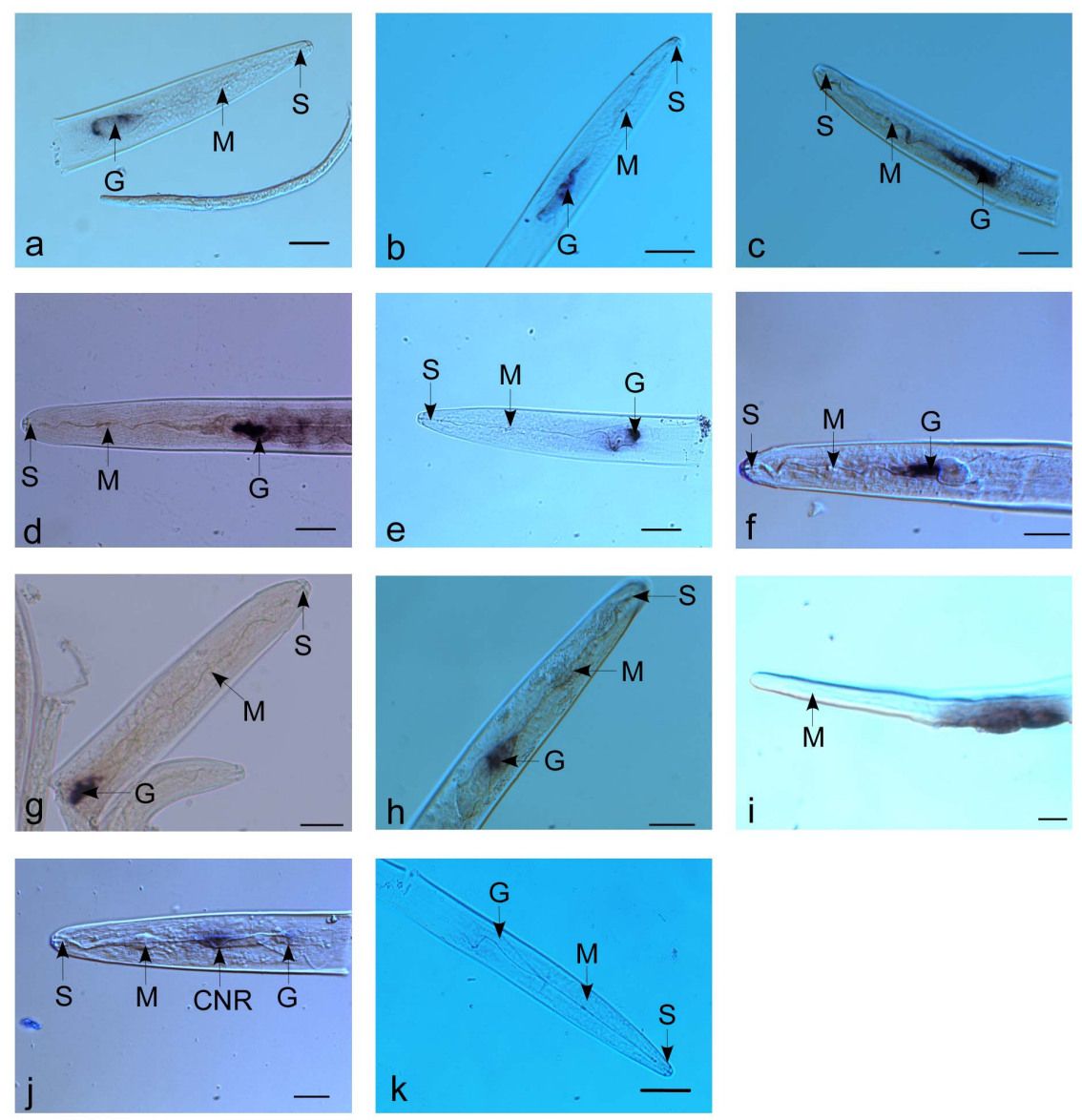

Figure 4. Localization of the effectors and expansin-like proteins from $D$. destructor using in situ hybridization. Section of the nematode incubated with antisense probe designed on putative effector genes: a, DDC05000(endo-1,4-beta-glucanase); $b$, DDC00149 (pactate lyase); c, Dd-exp-1 from D. destructor ; d, Dd-exp-2 from D. destructor ; e, DDC04837 (venom allergen antigen-like protein); f, DDC04927 (calreticulin protein); g, DDC02922 (annexin); h, DDC04384 (14-3-3b); i, DDC00459(flp protein); J, control. G, esophageal glands; S, stylet; M, metacorpus; CNR, circumpharyngeal nerve ring. Bar $=20 \mu \mathrm{l}$.

doi:10.1371/journal.pone.0069579.g004

(accession number GU373912) is 1,114 bp in length and contained a 900 bp ORF encoding 300 amino acids with an ATG start codon at the position 33 and a TAG stop codon at the position 936. The genomic DNA of $D d$-exp-1 and $D d$-exp-2 were 1,433 bp and 1,437 bp long from the start codon to the stop codon, respectively. The intron analysis showed that both contained one short intron $64 \mathrm{bp}$ and $88 \mathrm{bp}$, respectively) and one longer intron (440 bp and $446 \mathrm{bp}$, respectively). The splicing sites of the introns followed the canonical 'GU-AG rule'. The positions of the two introns of $D d-\exp -1$ were identical to those of $D d-\exp -2$. Moreover, the intron positions and numbers within both $D d$-exp-1 and $D d$-exp-2 were the same to that in Da-exp-1(GU129695) from D. africanus. However, each of Bx-exp-1, Bxexp-2, Bm-exp-1 and Bm-exp-2 from Bursaphelenchus spp. only has one intron located at the same position as the $D d-\exp -1$ and $D d-\exp -2$. Both Gr-expb1 (AJ556781) from G. rostochiensis and Ha-expb-1 (JN861113) from $H$. avenae have five introns, and the intron positions and phases are completely consistent between these sequences. Gr-expb1 and Ha-expb-1 share one intron position (the fifth) with $D d-\exp -1$ and $D d-\exp -2$ (Fig. 5).

The molecular weights of putative DD-EXP-1 and DD-EXP-2 proteins were $30.44 \mathrm{kDa}$ and $31.47 \mathrm{kDa}$ and the theoretical $\mathrm{pI}$ value were 4.88 and 5.05, respectively. Both DD-EXP-1 and DD-EXP-2 proteins had signal peptides for secretion with the most likely cleavage site between amino acids 19 and 20. The conserved domain search confirmed that the DD-EXP-1 and DD-EXP-2 contained two distinct domains, an expansin domain (amino acid region
20-147 for both proteins) coupled to a bacterial type cellulosebinding domain (amino acid region 222-309 for DD-EXP-1 and 212-300 for DD-EXP-2). DD-EXP-1 and DD-EXP-2 has 75\% and $73 \%$ identity with the DA-EXP-1 from $D$. africanus, respectively. In addition, DD-EXP-1 and DD-EXP-2 also had certain degrees of similarities to various hypothetical or unknown proteins from different microorganisms, and the pathogenicity or virulence factor precursors from Meloidogyne spp. with approximately 33\% identity. Moreover, the CBD domain of DD-EXP- 1 shared $62 \%$ and $63 \%$ identity with the CBMs in endo-1,4-glucanases from $D$. destructor and D. africanus (Dd-eng-1a,Dd-eng-1b and Da-eng-1), respectively.

Searching EST datasets from twenty nematode species with the expansin domain of DD-EXP-1 resulted in the identification of one matching contig from $D$. africanus, $H$. glycines, $B$. mucronatus, $B$. xylophilus and $P$. vulnus separately, two matching contigs from Xiphinema index, three matching contigs separately from $M$. paranaensis and $G$. rostochiensis, four matching contigs separately from $M$. arenaria and $M$. chitwoodi, five matching contigs separately from $M$. incognita and $M$. javanica, and eleven matching contigs from M. hapla. In addition, we conducted BLASTP searches on the predicted protein databases from $M$. incognita, M. hapla, B. xylophilus and G. pallida using the expansin domain of DD-EXP-1. Several expansin homologous proteins were identified from the four species of plant-parasitic nematodes (Table S3). 
Table 6. D. destructor transcripts similar to effector genes.

\begin{tabular}{|c|c|c|c|c|c|}
\hline \multirow[t]{2}{*}{ Chusters } & \multirow{2}{*}{ ESTs } & \multirow[t]{2}{*}{ Lenth (bp) } & \multicolumn{3}{|l|}{ Nor redundant Genebank } \\
\hline & & & Best hit description & Accession NO. & E-value \\
\hline DDC04999 & 4 & 552 & cellulase $[$ A. fragariae $]$ & AFI63769.1 & $4.00 \mathrm{E}-80$ \\
\hline DDC04626 & 4 & 927 & endo-1,4-beta-glucanase [D. africanus] & ACJ60676.1 & $3.00 \mathrm{E}-143$ \\
\hline DDC05000 & 79 & 952 & cellulase [A. fragariae] & AFD33558.1 & $3.00 \mathrm{E}-52$ \\
\hline DDC04253 & 3 & 263 & cellulase $[A$. fragariae] & AFI63769.1 & $1.00 \mathrm{E}-12$ \\
\hline DDC03578 & 2 & 580 & expansin-like protein $[D$. africanus $]$ & ADJ57307.1 & $1.00 \mathrm{e}-63$ \\
\hline DDC03579 & 2 & 541 & expansin-like protein [D. africanus] & ADJ57307.1 & $2.00 \mathrm{e}-92$ \\
\hline DDC00149 & 1 & 568 & Pectate lyase $[A$. avenae $]$ & BAI44499.1 & $3.00 \mathrm{E}-69$ \\
\hline DDC04104 & 2 & 566 & esophageal gland cell secretory protein $6[\mathrm{H}$. glycines $]$ & AAG21336.1 & $9.00 \mathrm{E}-35$ \\
\hline DDC04384 & 3 & 564 & 14-3-3b protein $[M$. incognita] & AAR85527.1 & $5.00 \mathrm{E}-52$ \\
\hline DDC00830 & 1 & 183 & calreticulin $[M$. incognita] & AAL40720.1 & $2.00 \mathrm{E}-19$ \\
\hline DDC04255 & 3 & 591 & calreticulin [B. xylophilus] & ADD82420.1 & $2.00 \mathrm{E}-71$ \\
\hline DDC04927 & 14 & 633 & calreticulin $[M$. incognita] & AAL40720.1 & $6.00 \mathrm{E}-68$ \\
\hline DDC03093 & 1 & 495 & VAP1 protein [G. rostochiensis] & CAD60978.1 & $2.00 \mathrm{E}-17$ \\
\hline DDC04838 & 4 & 620 & VAP1 protein [G. rostochiensis] & CAD60978.1 & 4.00E-19 \\
\hline DDC04839 & 4 & 696 & VAP1 protein [G. rostochiensis] & CAD60978.1 & $9.00 \mathrm{E}-26$ \\
\hline DDC03397 & 1 & 445 & VAP-2 [D. destructor] & ADC35399.1 & $2.00 \mathrm{E}-5$ \\
\hline DDC03835 & 2 & 607 & SEC-2 protein [Globodera pallida] & CAA70477.1 & $5.00 \mathrm{E}-40$ \\
\hline DDC02922 & 1 & 404 & annexin [B. xylophilus] & ACZ13330.1 & $3.00 \mathrm{E}-64$ \\
\hline DDC00061 & 1 & 516 & chitinase domain-containing protein 1 [Ascaris suum] & ADY45342.1 & $4.00 \mathrm{E}-36$ \\
\hline DDC01466 & 1 & 566 & probable chitinase 2-like [Bombus impatiens] & XP_003492468.1 & $9.00 \mathrm{E}-41$ \\
\hline DDC02490 & 1 & 315 & endo-1,3(4)-beta-glucanase [Exophiala dermatitidis] & EHY54200.1 & $4.00 \mathrm{E}-22$ \\
\hline DDC00721 & 1 & 441 & endo-1,3-1,4-b-glucanase [Metarhizium anisopliae] & EFZ01017.1 & $1.00 \mathrm{E}-31$ \\
\hline
\end{tabular}

doi:10.1371/journal.pone.0069579.t006

Expansin proteins from plant-parasitic nematodes were classified into three groups according to the domain structure (Fig. 6). In Group I, the expansin domain had a linker sequence and a cellulose binding domain $(\mathrm{CBD})$ at the $\mathrm{C}$ terminal, and the sequence of the domains as signal peptide-expansin domain-linkerCBD. DD-EXP-1, DD-EXP-2 and DA-EXP-1belonged to Group I. In Group II, the expansin proteins contain a signal peptide and an expansin domain without CBD. BX-EXPB-1, BX-EXPB-2, BX-EXPB-3, BM-EXB-1, BM-EXB-2 belong in Group II [23]. In Group III expansin-like proteins had a signal peptide followed by a cellulose binding domain at the $\mathrm{N}$ terminal that connected to an expansin-like domain by a linker sequence. HG-EXP-1, HA-EXP1, GR-EXP-1, GR-EXPB-1, MH-EXP and MI-EXP were included in Group III. In the genome sequences of $M$. incognita, M. hapla, B. xylophilus, and G. pallida, there are two copies of expansin gene sequences containing a $\mathrm{N}$-terminal CBD and an expansin-like domain. According the current evidences, expansin proteins from the cyst and root-knot nematodes were classed into Group II and Group III. The expansins of the pine wood nematode, $B$. xylophilus, and $P$. coffeae were in Group III, and the expansins of $D$. destructor and $D$. africanus were found in Group I.

Multiple sequences alignment of plant-parasitic nematodes and plant species indicated that the presence of a series of conserved cysteines marked as key signatures of the expansin family [60]. Three of the six cysteines were conserved in both plants and plantparasitic nematode expansin proteins. Two other cysteines were well conserved in all plant-parasitic nematode expansin proteins (Fig. 5). Another key motif of the plant expansin family is the HFD motif [60], but only the Hand $\mathrm{F}$ residues are conserved in the expansin proteins of plant-parasitic nematodes. In most of these sequences, the $\mathrm{F}$ is changed into one of the aliphatic amino acids (V, I, L or A). Similar conservation as well as an F to V conversion was found in the GR-EXPBl from $G$. rostochiensis, for which the cell wall expansin activity on the type II primary cell walls was confirmed $[46,58]$. This indicated that the amino acid change from $\mathrm{F}$ to $\mathrm{V}$ or other conversion does not affect the typical activity of expansin protein.

A phylogenetic tree was generated for the expansins from nematodes, plants, bacteria and fungi (Fig. 6). DD-EXP-1 and DD-EXP-2 were clustered together with the expansins from $D$. africanus and Bursaphelenchus spp. The root-knot nematode and cyst nematode expansins were clustered in other clades. The results indicated that the expansins from Ditylenchus spp. are closer to the expansins from Bursaphelechus spp. than to the expansins from the cyst and root-knot nematodes. Moreover, the identical position and phase of the shared introns in expansin domain suggested that the expansins from a wide range of plant-parasitic nematodes may have a common origin. The ancestral expansins of almost all plant-parasitic nematodes may only contain the expansin domain and was probably derived from horizontal gene transfer [61].

The tissue localization of DD-ENG-1 and DD-EXP-2 were assayed in $D$. destructor by in situ mRNA hybridization (Fig. $5 \mathrm{c}-\mathrm{d}$ ). The digoxigenin-labelled antisense cDNA probe hybridized specifically with transcripts accumulated within the two subventral pharyngeal gland cells of $D$. destructor. No hybridization signal was observed in sections with a control probe. Similar expression profiles have been described for expansins from other plantparasitic nematodes $[46,57,59]$, indicating that the reported 

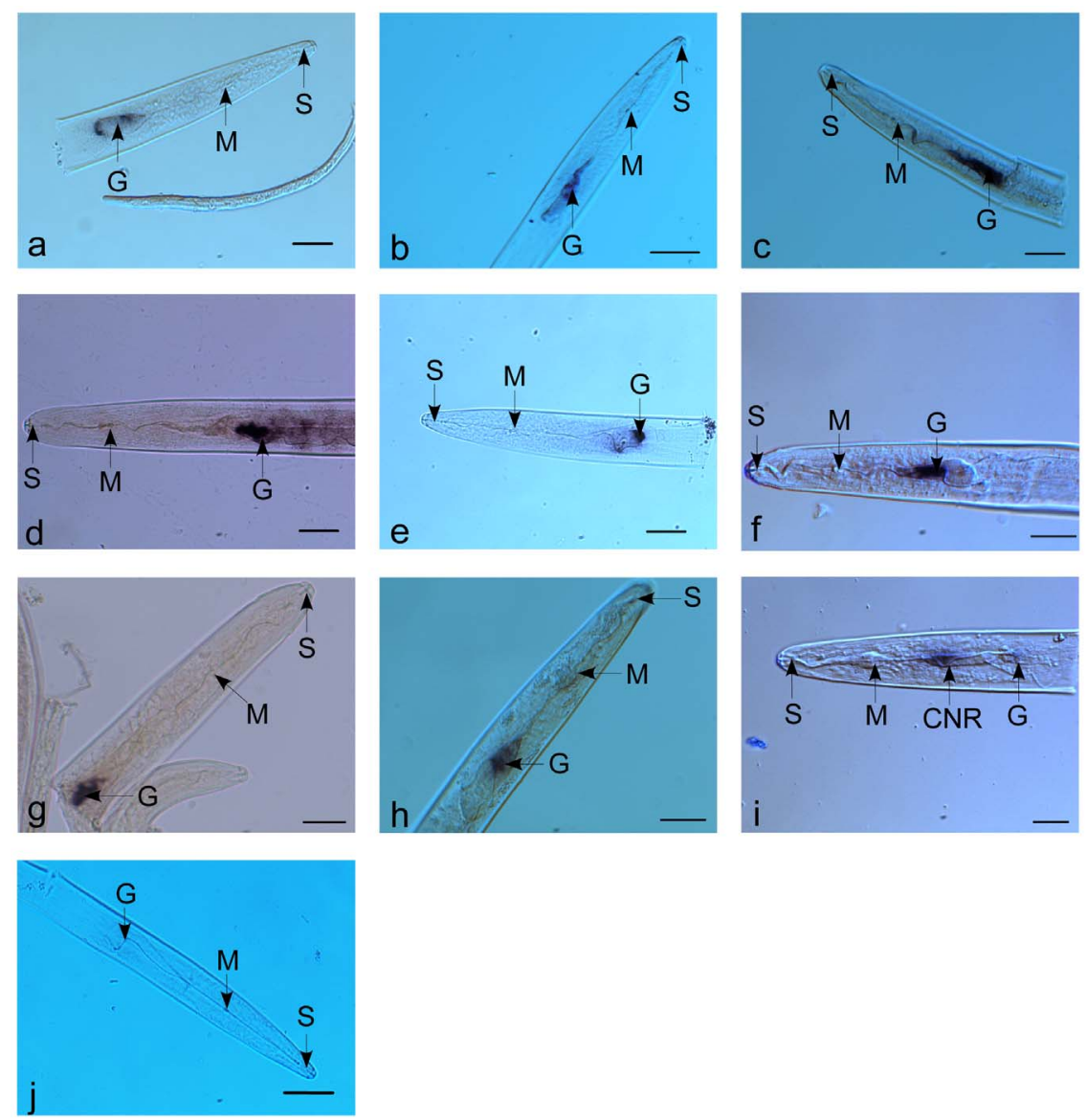

Figure 5. Multiple sequence alignment of DD-EXP-1 and DD-EXP-2 expansin proteins from $D$. destructor with that of other plant parasitic nematodes and plant. Residues identical to those of DD-EXP-1 and DD-EXP-2 are shaded black and similar residues are shaded grey. The conserved cysteines (C) in the expansin (like) family indicated with $\mathrm{C} 1$ to $\mathrm{C} 6$, the conserved cysteines in the expansin (like) proteins from plant parasitic nematodes are indicated by an asterisk $\left({ }^{*}\right)$. The positions of the introns are marked by D1 in DD-EXP-1 and DD-EXP-2, D2 in DA-EXP-1, H in HA-EXPB-1, B in BX-EXP-1 and BM-EXP-1, and G in GR-EXP-1. White triangles, black triangles and black diamond represent phase 0,1 and 2 introns, respectively. Da, Ditylenchus africanus; Bx, Bursaphelenchus xylophilus; MJ, Meloidogyne javanica; MI, M. incognita; MH, M. hapla; $\mathrm{HG}$, Heterodera glycine; HA, H. avenae; GP, Globodera pallida; GR, G. rostochiensis. PPAL [AAG52887] from Nicotiana tabacum. doi:10.1371/journal.pone.0069579.g005

expansins from the plant parasitic nematodes may share a similar function during infection of a plant by the nematode.

Expansins are known to weaken non-covalent interactions between cellulose and hemicellulose polymers thereby inducing plant cell wall extension [62]. The expansin proteins in D. destructor have a predicted signal peptide at the N-terminal, plus their expression in the subventral pharyngeal gland cells suggested that the DD-EXP-1 and DD-EXP-2 proteins were most likely secreted into the host tissues by $D$. destructor. The phylogenetic analysis together with the identical position and phase of the share intron in expansin domain from plant-parasitic nematodes suggested that the expansins of plant-parasitic nematodes may have a common ancestor. In addition, the expansin proteins from plant-parasitic nematodes contain three different protein domain variants, implying that expansins are likely to have evolved several times during the nematode and plant interaction.

\section{Conclusions}

We have described the first detailed molecular analysis of the important plant-parasitic nematode $D$. destructor by a systematic characterization of ESTs. 9800 ESTs were obtained from a mixed stage cDNA library of $D$. destructor and over 5008 unigenes were identified. Among unigenes, 1391 specific to D. destructor and 31 specific to Ditylenchus spp. had no similarity to any known genes. In addition, 22 sequences similar to published nematode effectors and 391 secretome members were identified from $D$. destructor ESTs. In situ hybridization assays revealed that the most abundant effectors were localized in the pharyngeal gland cells.

Although the number of ESTs analyzed in this study is not large enough to represent the whole profile of the $D$. destructor transcriptome, the set of identified and validated genes, which are involved in plant and fungi cell wall degradation or modification, supported the fact that $D$. destructor can either be a plant parasite or a fungal feeder. This is the first report of 1, 3-beta-glucanase in nematode species of Anguinae (Nematoda: Tylenchida). Examining the phylogenetic evolution of the $D$. destructor expansin structures suggested that the expansin domain from plant-parasitism nematodes may have a common ancestor, but the evolution of expansin proteins in plant-parasitic nematodes involved domain shuffling.

In conclusion, the ESTs of $D$. destructor are not only useful in understanding the molecular biology of the sedentory and the migratory endo-parasitic nematodes, but also offer a direct molecular basis to distinguish $D$. destructor and $D$. africanus, which were previously described as the same species. In addition, this dataset also provides a resource for the upcoming whole genomic 

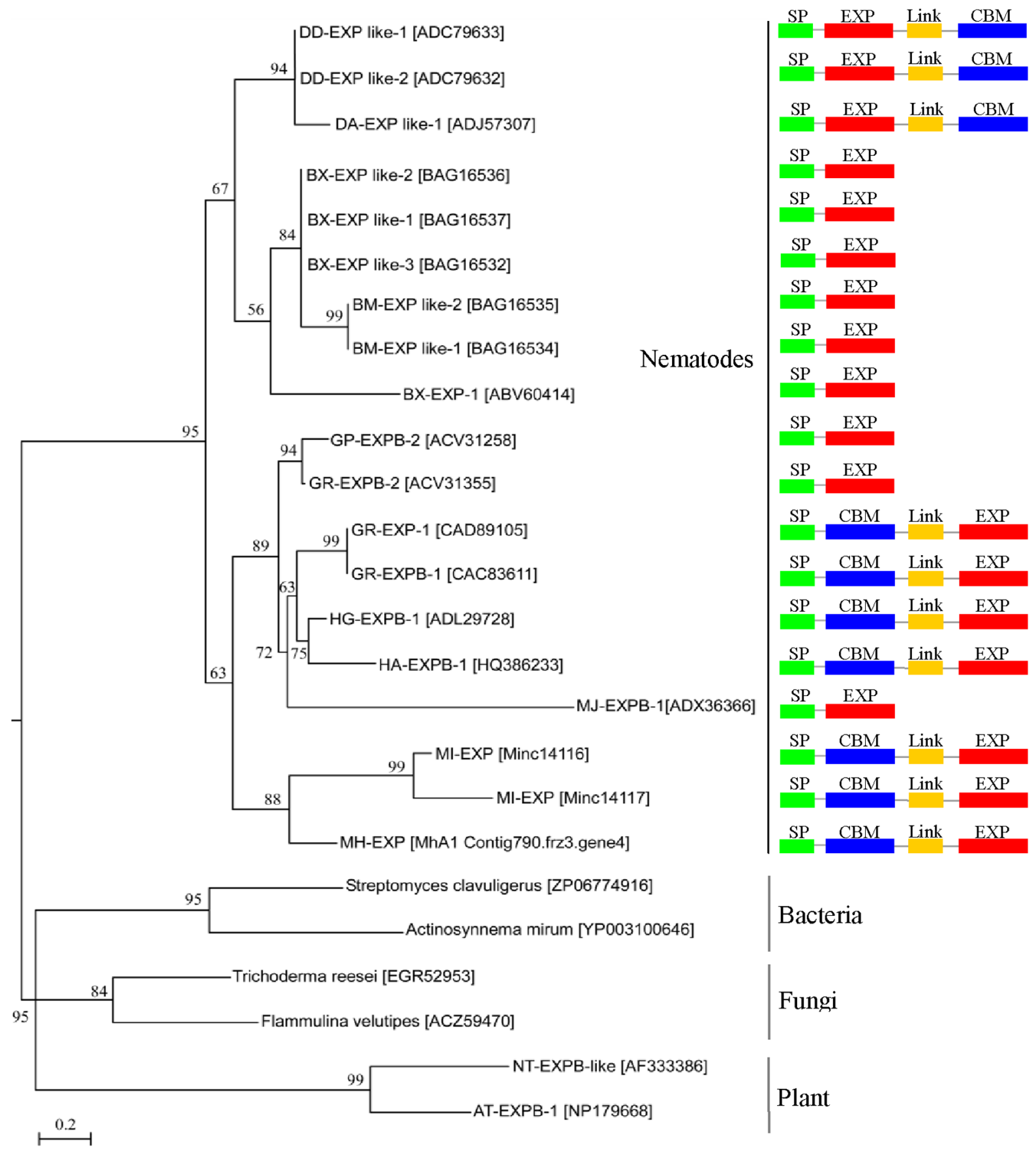

\section{Bacteria}

Fungi

Plant

Figure 6. Phylogenetic tree of selected expansin proteins generated using maximum likelihood of PhyML. Numbers next to the branches indicate the bootstrap value calculated from 1000 replicates. The Genbank accession number of expansin proteins from $D$. africanus (DaEXP-1), B. xylophilus (BX-EXPB-1, BX-EXPB-2, BX-EXPB-3, BX-EXP-1), B. mucronatus (BM-EXPB-1, BM-EXPB-2), G. rostochiensis (GR-EXPB-1, GR-EXPB-2 and GR-EXP-1), G. pallida (GP-EXP-2B) , H. avenae(HA-EXPB-1), H. glycines (HG-EXPB-1), M. javanica (MJ-EXPB-1) and the prediction proteins of genomes from M. incognita (MI-EXP), M. hapla (MH-EXP), bacteria, fungi and plant are indicated in brackets. doi:10.1371/journal.pone.0069579.g006

sequencing that will reveal the full complement of potential effectors present in $D$. destructor.

\section{Supporting Information}

Table S1 Gene Ontology mappings for D. destructor clusters. Note that individual GO categories can have multiple mappings. To obtain the complete GO mapping, a node sequence filter in the
GO graph was used: 50 for biological process, 20 for molecular function, and 20 for the cellular component.

\section{(XLS)}

Table S2 The potentially secreted proteins of $D$. destructor. TBLASTX searches $(\mathrm{E}<1 \mathrm{e}-5)$ of clusters of $D$. destructor against $D$. africanus ESTs and $\mathrm{Nr}$ databases.

(XLSX) 
Table S3 The homologous expansins in other nematodes. BLASTX searches $(\mathrm{E}<1 \mathrm{e}-5)$ of expansin domain of DD-EXP-1 against NR databases, tBLASTX searches $(\mathrm{E}<1 \mathrm{e}-5)$ of expansin domain of DD-EXP-1 against EST database from twenty species of plant-parasitic nematodes and BLASTP searches $(E<1 \mathrm{e}-5)$ of expansin domain of DD-EXP-1 against genome datasets of plantparasitic nematodes (B. xylophilus, M. incognita, M. hapla, G. pallida) (DOCX)

\section{Acknowledgments}

Prof. Roland Perry (Rothamsted Research, UK) and Prof. John Jones (The James Hutton Institute Invergowrie, Dundee) are thanked for their scientific advice and revision of the manuscript.

\section{References}

1. Mitreva M, Mardis ER (2009) Large-scale sequencing and analytical processing of ESTs. Methods Mol Biol 533: 153-187.

2. Palomares-Rius JE, Hedley PE, Cock PJ, Morris JA, Jones JT, et al. (2012) Comparison of transcript profiles in different life stages of the nematode Globodera pallida under different host potato genotypes. Mol Plant Pathol 13: 1120-1134.

3. Gheysen G, Mitchum MG (2011) How nematodes manipulate plant development pathways for infection. Curr Opin Plant Biol 14: 415-421.

4. Haegeman A, Mantelin S, Jones JT, Gheysen G (2012) Functional roles of effectors of plant-parasitic nematodes. Gene 492: 19-31

5. Dubreuil G, Magliano M, Deleury E, Abad P, Rosso MN (2007) Transcriptome analysis of root-knot nematode functions induced in the early stages of parasitism. New Phytol 176: 426-436.

6. de Boer JM, McDermott JP, Wang XH, Maier T, Qu F, et al. (2002) The use of DNA microarrays for the developmental expression analysis of cDNAs from the oesophageal gland cell region of Heterodera glycines. Mol Plant Pathol 3: 261-270.

7. Popeijus M, Blok VC, Cardle L, Bakker E, Phillips MS, et al. (2000) Analysis of genes expressed in second stage juveniles of the potato cyst nematodes Globodera rostochiensis and $G$. pallida using the expressed sequence tag approach. Nematology 2: 567-574.

8. Jacob J, Mitreva M, Vanholme B, Gheysen G (2008) Exploring the transcriptome of the burrowing nematode Radopholus similis. Mol Genet Genomics 280: 1-17

9. Kikuchi T, Aikawa T, Kosaka H, Pritchard L, Ogura N, et al. (2007) Expressed sequence tag (EST) analysis of the pine wood nematode Bursaphelenchus xylophilus and B. mucronatus. Mol Biochem Parasit 155: 9-17.

10. Kang M-J, Kim Y-H, Hahn B-S (2010) Expressed sequence tag analysis generated from a normalized full-length cDNA library of the root-knot nematode (Meloidogyne incognita). Genes Genom 32: 553-562.

11. Haegeman A, Jacob J, Vanholme B, Kyndt T, Mitreva M, et al. (2009) Expressed sequence tags of the peanut pod nematode Ditylenchus africanus: The first transcriptome analysis of an Anguinid nematode. Mol Biochem Parasit 167: 32- 40 .

12. Karim N, Jones JT, Okada H, Kikuchi T (2009) Analysis of expressed sequence tags and identification of genes encoding cell-wall-degrading enzymes from the fungivorous nematode Aphelenchus avenae. BMC Genomics 10:525.

13. Roze E, Hanse B, Mitreva M, Vanholme B, Bakker J, et al. (2008) Mining the secretome of the root-knot nematode Meloidogyne chitwoodi for candidate parasitism genes. Mol Plant Pathol 9: 1-10.

14. Gao BL, Allen R, Maier T, Davis EL, Baum TJ, et al. (2001) Identification of putative parasitism genes expressed in the esophageal gland cells of the soybean cyst nematode Heterodera glycines. Mol Plant Microbe In 14: 1247-1254.

15. Huang GZ, Dong RH, Maier T, Allen R, Davis EL, et al. (2004) Use of solidphase subtractive hybridization for the identification of parasitism gene candidates from the root-knot nematode Meloidogyne incognita. Mol Plant Pathol 5: 217-222.

16. Vanholme B, Mitreva M, Van Criekinge W, Logghe M, Bird D, et al. (2006) Detection of putative secreted proteins in the plant-parasitic nematode Heterodera schachtii. Parasitol Res 98: 414-424.

17. Furlanetto C, Cardle L, Brown DJF, Jones JT (2005) Analysis of expressed sequence tags from the ectoparasitic nematode Xiphinema index. Nematology 7: 95-104.

18. Bellafiore S, Shen ZX, Rosso MN, Abad P, Shih P, et al. (2008) Direct identification of the Meloidogyne incognita secretome reveals proteins with host cell reprogramming potential. PLoS Pathog 4: e1000192.

19. Abad P, Gouzy J, Aury JM, Castagnone-Sereno P, Danchin EG, et al. (2008) Genome sequence of the metazoan plant-parasitic nematode Meloidogyne incognita. Nat Biotechnol 26: 909-915.

20. Kikuchi T, Cotton JA, Dalzell JJ, Hasegawa K, Kanzaki N, et al. (2011) Genomic Insights into the Origin of Parasitism in the Emerging Plant Pathogen Bursaphelenchus xylophilus. PLoS Pathog 7: e1002219.

21. Opperman CH, Bird DM, Williamson VM, Rokhsar DS, Burke M, et al. (2008) Sequence and genetic map of Meloidogyne hapla: A compact nematode genome for plant parasitism. Proc Natl Acad Sci U S A 105: 14802-14807.

\section{Author Contributions}

Analyzed the data: HP. Contributed reagents/materials/analysis tools: XFH. Wrote the paper: HP DLP BLG QY. Conceived of the study: DLP. Participated in study design and coordination the experiments: DLP. Carried out the bioinformatics studies: HP. Participated in the sequence analysis: HP. Drafted the manuscript: HP. Participated in situ hybridization: WKH. Carried out the cDNA library building: HBL. Read and approved the final manuscript: HP BLG LAK QY WKH XFH HBL DLP.

22. Haegeman A, Bauters L, Kyndt T, Rahman MM, Gheysen G (2012) Identification of candidate effector genes in the transcriptome of the rice root knot nematode Meloidogyne graminicola. Mol Plant Pathol 14:379-390.

23. Haegeman A, Joseph S, Gheysen G (2011) Analysis of the transcriptome of the root lesion nematode Pratylenchus coffeae generated by 454 sequencing technology. Mol Biochem Parasitol 178: 7-14.

24. Nicol P, Gill R, Fosu-Nyarko J, Jones MG (2012) de novo analysis and functional classification of the transcriptome of the root lesion nematode, Pratylenchus thomei, after 454 GS FLX sequencing. Int J Parasitol 42: 225-237.

25. (2008) Ditylenchus destructor and Ditylenchus dipsaci. EPPO Bulletin 38: 363-373.

26. Yu Q Zaida MA, Hughes B, Celetti M (2012) Discovery of Potato Rot Nematode, Ditylenchus destructor, Infesting Garlic in Ontario, Canada. Plant Dis 96: 297.

27. Huang WK, Peng DL, Zhang DS, Jiang HY, Ding Z, et al. (2010) Assessment of genetic variability in population of Ditylenchus destructor (Thorne 1945) (Tylenchida: Anguinidae) from China. Russ J Nematol 18: 19-30.

28. Mc Donald A, Loots G, Fourie H, De Waele D (1995) A microplot study on Ditylenchus africanus population densities and damage symptoms on groundnut in relation to commercial yields. Nematology 7: 647-653.

29. Jones BL, De Waele D (1988) First report of Ditylencus destructor in pods and seeds of peanut. Plant Dis 72: 453 .

30. Young H, Seung H (1995) In vitro culture and factors affecting population changes of Ditylenchus destructor of ginseng. Korean J Plant Pathol 11: 39-46.

31. Burge C, Karlin S (1997) Prediction of complete gene structures in human genomic DNA. J Mol Biol 268: 78-94.

32. Petersen TN, Brunak S, von Heijne G, Nielsen H (2011) SignalP 4.0: discriminating signal peptides from transmembrane regions. Nat Methods 8: 785-786.

33. Conesa A, Gotz S, Garcia-Gomez JM, Terol J, Talon M, et al. (2005) Blast2GO: a universal tool for annotation, visualization and analysis in functional genomics research. Bioinformatics 21: 3674-3676.

34. Ye J, Fang L, Zheng H, Zhang Y, Chen J, et al. (2006) WEGO: a web tool for plotting GO annotations. Nucleic Acids Res 34: W293-297.

35. Mao X, Cai T, Olyarchuk JG, Wei L (2005) Automated genome annotation and pathway identification using the KEGG Orthology (KO) as a controlled vocabulary. Bioinformatics 21: 3787-3793.

36. de Boer JM, Yan Y, Smant G, Davis EL, Baum TJ (1998) In-situ Hybridization to Messenger RNA in Heterodera glycines. J Nematol 30: 309-312.

37. Peng H, Hu X, Huang W, He W, Peng D (2011) Cloning and localization analysis of a novel FMRFamide like neuropeptide gene (Dd-flp-1) from migration plant parasitic nematode (Ditylenchus destructor) on sweet potato in China. J Agr Biotech 19: 924-931.

38. Tamura K, Peterson D, Peterson N, Stecher G, Nei M, et al. (2011) MEGA5: molecular evolutionary genetics analysis using maximum likelihood, evolutionary distance, and maximum parsimony methods. Mol Biol Evol 28: 2731-2739.

39. Dereeper A, Guignon V, Blanc G, Audic S, Buffet S, et al. (2008) Phylogeny.fr: robust phylogenetic analysis for the non-specialist. Nucleic Acids Res 36: 465469

40. Wang P, Zhao J, Corsi AK (2006) Identification of novel target genes of Cetwist and CeE/DA. Dev Biol 293: 486-498.

41. Mitreva M, Jasmer DP, Appleton J, Martin J, Dante M, et al. (2004) Gene discovery in the adenophorean nematode Trichinella spiralis: an analysis of transcription from three life cycle stages. Mol Biochem Parasitol 137: 277-291.

42. Long H, Peng H, Huang W, Wang G, Gao B, et al. (2012) Identification and molecular characterization of a new $\beta$-1,4-endoglucanase gene (Ha-eng-1a) in the cereal cyst nematode Heterodera avenae. Eur J Plant Pathol 134: 391-400.

43. Peng H, Peng DL, Huang WK (2009) Molecular cloning and sequence analysis of a new 1,4-endoglucanase (Dd-eng-1b) gene from migratoin plant parasitic nematode Ditylenchus destructor on sweetpotato in China. J Agr Biotech 17: 10351041.

44. Gao BL, Allen R, Davis EL, Baum TJ, Hussey RS (2004) Developmental expression and biochemical properties of a beta-1,4-endoglucanase family in the soybean cyst nematode, Heterodera glycines. Mol Plant Pathol 5: 93-104. 
45. Smant G, Stokkermans JPWG, Yan YT, De Boer JM, Baum TJ, et al. (1998) endogenous cellulases in animals: Isolation of beta-1,4-endoglucanase genes from two species of plant-parasitic cyst ematodes. Proc Natl Acad Sci USA 95: 4906-4911.

46. Qin L, Kudla U, Roze EHA, Goverse A, Popeijus H, et al. (2004) Plant degradation: A nematode expansin acting on plants. Nature 427: 30.

47. Popeijus H, Overmars H, Jones J, Blok V, Goverse A, et al. (2000) Enzymology Degradation of plant cell walls by a nematode. Nature 406: 36-37.

48. Gheysen G, Vanholme B (2007) RNAi from plants to nematodes. Trends Biotechnol 25: 89-92.

49. Lilley CJ, Davies LJ, Urwin PE (2012) RNA interference in plant parasitic nematodes: a summary of the current status. Parasitology 139: 630-640.

50. Kikuchi T, Shibuya H, Jones JT (2005) Molecular and biochemical characterization of an endo-beta-1,3-glucanase from the pinewood nematode Bursaphelenchus xylophilus acquired by horizontal gene transfer from bacteria. Biochem J 389: 117-125.

51. Gao B, Allen R, Maier T, McDermott JP, Davis EL, et al. (2002) Characterisation and developmental expression of a chitinase gene in Heterodera glycines. In J Parasitol 32: 1293-1300.

52. Jaouannet M, Magliano M, Arguel MJ, Gourgues M, Evangelisti E, et al. (2013) The root-knot nematode calreticulin Mi-CRT is a key effector in plant defense suppression. Mol Plant Microbe Interact 26: 97-105.

53. Patel N, Hamamouch N, Li C, Hewezi T, Hussey RS, et al. (2010) A nematode effector protein similar to annexins in host plants. J Exp Bot 61: 235-248.

54. Kang JS, Koh YH, Moon YS, Lee SH. (2012) Molecular properties of a venom allergen-like protein suggest a parasitic function in the pinewood nematode Bursaphelenchus xylophilus. Int J Parasitol 42: 63-70.
55. Jaubert S, Laffaire JB, Ledger TN, Escoubas P, Amri EZ, et al. (2004) Comparative analysis of two 14-3-3 homologues and their expression pattern in the root-knot nematode Meloidogyne incognita. In J Parasitol 34: 873-880.

56. Elling AA, Mitreva M, Gai X, Martin J, Recknor J, et al. (2009) Sequence mining and transcript profiling to explore cyst nematode parasitism. BMC Genomics 10: 58 .

57. Kikuchi T, Li HM, Karim N, Kennedy MW, Moens M, et al. (2009) Identification of putative expansin-like genes from the pine wood nematode, Bursaphelenchus xylophilus, and evolution of the expansin gene family within the Nematoda. Nematology 11: 355-364.

58. Kudla U, Qin L, Milac A, Kielak A, Maissen C, et al. (2005) Origin, distribution and 3D-modeling of Gr-EXPB1, an expansin from the potato cyst nematode Globodera rostochiensis. FEBS Lett 579: 2451-2457.

59. Long H, Peng D, Huang W, Liu Y, Peng H (2012) Identification of a putative expansin gene expressed in the subventral glands of the cereal cyst nematode Heterodera avenae. Nematology pp. 571-577.

60. Cosgrove DJ (2000) New genes and new biological roles for expansins. Curr Opin Plant Biol 3: 73-78.

61. Haegeman A, Kyndt T, Gheysen G (2010) The role of pseudo-endoglucanases in the evolution of nematode cell wall modifying proteins. J Mol Evol 70: 441452.

62. McQueen-Mason S, Cosgrove DJ (1994) Disruption of hydrogen bonding between plant cell wall polymers by proteins that induce wall extension. Proc Natl Acad Sci U S A 91: 6574-6578. 